\title{
APRENDIZAGEM E DESENVOLVIMENTO: EVENTOS INSTRUCIONAIS EM UM CURSO DE PÓS-GRADUAÇÃo
}

\section{LEARNING AND DEVELOPMENT: INSTRUCTIONAL EVENTS IN AN POSTGRADUATE PROGRAM}

\section{APRENDIZAJE Y DESARROLLO: EVENTOS DE INSTRUCCIÓN EN UN CURSO DE POSTGRADO}

Recebido: 16/07/2015 Aprovado: 25/11/2015
Fabio Scorsolini-Comin 1 Manoel Antônio dos Santos ${ }^{2}$

O objetivo do estudo foi delinear as principais contribuições da teoria da aprendizagem de Robert Gagné para a educação à distância, a partir da análise dos eventos instrucionais de um curso de pós-graduação lato sensu. A estratégia metodológica foi o estudo de caso. Os nove eventos instrucionais propostos pelo modelo foram analisados a partir de elementos do curso de pósgraduação, como material didático, modelo pedagógico, ferramentas de aprendizagem, avaliação e transferência. Os resultados destacaram a importância dos feedbacks coletivos para orientar os alunos e da transferência da aprendizagem para contextos vinculados à prática em gestão social. Conclui-se que os eventos instrucionais constituem recursos potenciais para a organização de modelos instrucionais à distância, agregando qualidade ao ensino e favorecendo aprendizagens que promovam transformações no desenvolvimento dos alunos.

Descritores: Aprendizagem; Educação de pós-graduação; Educação à distância.

This study aims to outline the main contributions of Robert Gagné learning theory to the Elearning education based on the analysis of instructional events of a lato sensu Postgraduation Course. The methodological strategy was performed as a case study. Nine proposed instructional events by the model were analyzed from the postgraduation course such as didactic material, pedagogical model, learning tools, evaluation as well as transference. The outcomes revealed the importance on collective feedbacks toward students' orientation along with learning transference to contexts linked to the practice of social management. It was concluded that instructional events make part of potential resources to the organization of E-learning instructional models by adding teaching quality, besides making it possible learning which promotes changes in the student development.

Descriptors: Learning; Educatión graduate; Education distance.

El objetivo de este estudio fue delinear las principales aportaciones de la teoría del aprendizaje de Robert Gagné para educación a distancia, a partir del análisis de eventos instruccionales de un curso de posgrado lato sensu. La estrategia metodológica fue el estudio de caso. Se analizaron los nueve eventos instruccionales propuestos por el modelo en los elementos del curso de postgrado, como material didáctico, modelo pedagógico, herramientas de aprendizaje, evaluación y transferencia. Los resultados destacan la importancia de la retroalimentación colectiva para guiar a los estudiantes y la transferencia de aprendizaje en contextos relacionados con la gestión. Se concluye que los eventos instruccionales son recursos potenciales para la organización de modelos instruccionales en la distancia, agregando calidad a la enseñanza y fomentando el aprendizaje que promueven transformaciones en el desarrollo de los estudiantes.

Descriptores: Aprendizaje; Educación de posgrado; Educación a distancia.

\footnotetext{
1 Psicólogo. Especialista em Gestão da Educação. Mestre e Doutor em Psicologia. Pós Doutor em Tratamento e Prevenção Psicológica. Coordenador do Programa de Pós-graduação em Psicologia e Professor Adjunto II do Departamento de Psicologia da Universidade Federal do Triângulo (UFTM). Líder do PROSA - Laboratório de Investigações sobre Práticas Dialógicas e Relacionamentos Interpessoais (UFTM/CNPq) Mineiro. fabioscorsolini@gmail.com.

2 Psicólogo. Mestre e Doutor em Psicologia Clínica. Livre-Docente pela Universidade de São Paulo (USP). Professor Associado III da Faculdade de Filosofia, Ciências e Letras de Ribeirão Preto - USP. Bolsista de Produtividade em Pesquisa do CNPq.masantos@ffclrp.usp.br
} 


\section{INTRODUÇÃO}

T a cibercultura, os modelos de aprendizagem são considerados cada 1 vez mais transitórios, haja vista que diferentes ferramentas e elementos são criados constantemente para facilitar, agilizar ou promover os processos de ensinoaprendizagem. Nesse novo modelo de compreender a relação entre pessoas e conhecimentos, aprender a aprender é uma tarefa que cada vez mais ganha relevância, uma vez que os recursos tecnológicos tornam-se obsoletos a cada dia, fazendo com que as pessoas tenham que lidar com um repertório cada vez mais vasto de informações e de trânsito de dados. Essas informações podem incluir ou excluir o sujeito em rede.

Nesse cenário em constante mutação, saber como lidar com as novas tecnologias da informação e da comunicação (NTIC) não se torna apenas uma necessidade, mas também uma possibilidade de inserção em ambientes que fazem parte da vida cotidiana, de modo que dominá-las também passa a ser uma forma de existir no mundo contemporâneo ${ }^{1,2}$. A ciência do desenvolvimento humano já tem incorporado em suas discussões o acesso às tecnologias e de que modo as mesmas tem interferido ou possibilitado novas leituras da realidade a partir de sua presença cada vez destacada na vida cotidiana ${ }^{3}$. As tecnologias como mediadoras dos processos de desenvolvimento e de aprendizagem, tais como consideradas por autores de grande envergadura teórica como Vigotski, Piaget e Bakhtin, têm adquirido um caráter cada vez mais expressivo, de modo não apenas a instrumentalizar ou potencializar uma ação educativa ou desenvolvimental ${ }^{4}$, mas também de lhe conferir um sentido novo, uma função diferente: a de se comunicar no mundo contemporâneo e a de pertencer a essa nova malha de configurações.

No âmbito dessas transformações, a educação a distância (EAD) não é mais apresentada como uma simples possibilidade ou alternativa aos modelos considerados mais tradicionais, mas uma modalidade de ensino-aprendizagem que faz parte de diferentes currículos, de treinamentos, de processos de formação profissional e de propostas pedagógicas relacionadas a diferentes áreas do conhecimento, como a saúde pública e de cuidados em saúde 5 .

Na EAD, a presença das NTIC oferece um contexto para a aprendizagem e suporte básico para que pessoas possam se conectar umas às outras e construir e compartilhar informações e conhecimentos ${ }^{2}$. A aprendizagem não é mais concebida como um processo assimétrico, que parte daquele que detém mais conhecimentos para aqueles que precisam ser treinados, mas coloca os aprendentes e os professores em uma posição colaborativa e de construção conjunta dos saberes necessários a determinados grupos. Nesse sentido, alguns modelos teóricos têm emergido para dar suporte aos estudos de tais mudanças no contexto da cibercultura, ao passo que os autores, considerados mais tradicionais, têm sido convidados novamente para debater o atual cenário da aprendizagem na sociedade do conhecimento. É por meio desse diálogo que as teorias da aprendizagem vêm incorporando os atuais cenários educativos em suas perspectivas teóricas, revisando não apenas o modo como as pessoas se relacionam com a aprendizagem, mas como a aprendizagem efetivamente passa a ser um aspecto essencial nos modos como se organizam e se conecta na cibercultura ${ }^{2}$.

Um dos autores cuja obra tem sido resgatada de modo expressivo nos últimos anos é o psicólogo norte-americano Robert M. Gagné6-11, que pode ser considerado um dos fundadores da teoria do processamento da informação. Gagné viveu entre 1916 e 2002, graduou-se em Psicologia pela Universidade de Yale (1937), lecionou na Universidade da Califórnia, na Princeton University e na Florida State University. Foi pioneiro da chamada ciência da instrução durante a Segunda Guerra Mundial, quando desenvolveu treinamentos para pilotos da Força Aérea dos Estados Unidos. Também se envolveu na aplicação de conceitos da teoria de instrução para projetos de treinamentos e 
multimídias. Em seus projetos instrucionais, considerava a existência de diferentes tipos de aprendizagem (aprendizagem de sinal, de estímulo-resposta, cadeias motoras, associações verbais, discriminações, conceitos, regras e regras de ordem superior). Acreditava que diferentes condições de ensino são mais suscetíveis de possibilitar a assunção dos diferentes tipos de aprender. Gagné conferiu importância às condições que facilitam a obtenção dos resultados da aprendizagem ${ }^{6}$. Sua teoria tem sido amplamente discutida justamente por oferecer respostas práticas aos desafios dos contextos de aprendizagem, como planejar programas instrucionais, o que tem possibilitado que cursos na modalidade à distância sejam desenvolvidos e possam atingir suas metas instrucionais a partir de um modelo organizado e devidamente coordenado de ações em educação.

Este estudo teve por objetivo delinear as principais contribuições da teoria da aprendizagem de Robert Gagné para a educação à distância, a partir da análise dos eventos instrucionais presentes em um curso de pós-graduação lato sensu.

\section{MÉTODO}

Tipo de estudo: trata-se de um estudo de caso, desenvolvido no contexto de um programa de pós-graduação lato sensu na modalidade a distância. A estratégia do estudo de caso foi empregada de modo a possibilitar uma análise pormenorizada dos eventos instrucionais relacionados à aprendizagem nesse contexto de formação profissional.

Caso analisado: um curso de pósgraduação lato sensu em desenvolvimento regional sustentável, na modalidade a distância. Promovido por um consórcio entre universidades federais e um instituto de ensino e pesquisa, o curso foi direcionado a gestores de um banco público para o desenvolvimento de estratégias negociais para a sustentabilidade ${ }^{12}$. Além das atividades a distância, realizadas em ambiente virtual de aprendizagem (AVA), os alunos realizavam um estágio nas comunidades em desenvolvimento, denominado residência social13, que era orientado por tutores especializados.

Corpus de análise: situações educacionais analisadas nos nove eventos instrucionais que, segundo Gagné, facilitariam a aprendizagem: (1) ganhar a atenção; (2) informar os aprendizes do objetivo; (3) estimular a recordação da aprendizagem anterior; (4) apresentar o estímulo; (5) proporcionar orientação para a aprendizagem; (6) eliciar o desempenho (resposta); (7) proporcionar feedback; (8) avaliar o desempenho; (9) estimular a retenção e a transferência6-11. No presente caso, se exemplificará e problematizará cada um desses eventos a partir de observações minuciosas realizadas no modelo instrucional adotado. Essas observações levam em conta os seguintes elementos: modelo pedagógico do curso, público-alvo, seleção dos candidatos, material didático, formas de avaliação e transferência de aprendizagem. A discussão será amparada no referencial teórico de Gagné.

Referencial teórico: a fundamentação deste estudo de caso se assenta na teoria da aprendizagem de Gagné. Essa teoria tem uma base híbrida, já que mescla elementos comportamentais e cognitivos ${ }^{14-15}$. Esse modelo tem sido empregado em diferentes estudos da área da educação a distância, de modo a facilitar a compreensão de como as hipermídias podem favorecer o aprendizado dos alunos em programas de formação profissional ou de treinamentos. Esse modelo tem recebido a atenção não apenas de educadores, mas também de psicólogos, administradores e enfermeiros interessados no planejamento de instruções que visam ao ensino de determinadas competências, seja no ambiente organizacional ou no ensino em Enfermagem, por exemplo ${ }^{16}$. As bases do pensamento de Gagné são empregadas no planejamento de plataformas de aprendizagem e de programas de cursos em EAD, contribuindo para organizar não apenas os conteúdos curriculares, mas o modo como essa sistematização pode favorecer com que essas iniciativas alcancem seus objetivos educacionais. A partir dessas considerações, 
pode-se destacar que o modelo proposto por Gagné é um dos que mais oferecem apoio para se pensar a aprendizagem na contemporaneidade não apenas em ambientes tradicionais de ensino, como a sala de aula, mas também nos ambientes virtuais de aprendizagem (AVA) ou em plataformas organizadas em rede.

Uma das primeiras discussões tecidas na obra de Gagné refere-se à diferença fundamental entre desenvolvimento e aprendizagem ${ }^{7}$. Os dois conceitos referem-se, basicamente, aos processos de mudança. No entanto, o desenvolvimento seria caracterizado pelas mudanças de longo prazo, de caráter mais permanente, ao passo que a aprendizagem envolveria as mudanças de curto prazo. Apesar dessa diferença, ambas as noções estariam intimamente relacionadas, uma vez que o desenvolvimento do comportamento seria resultado dos efeitos cumulativos da aprendizagem, ou seja, as diversas aprendizagens, de curto prazo, poderiam dar origem a mudanças mais significativas e perenes que desencadeariam processos de desenvolvimento no longo prazo. Por isso, o destaque de sua obra está na aprendizagem como motor para o desenvolvimento, de modo que as suas contribuições têm sido investigadas mais na área educacional e suas interfaces (Psicologia Educacional, Psicologia da Educação, Psicologia Escolar, Psicologia da Educação Virtual) do que na Psicologia do Desenvolvimento ${ }^{14,15}$.

Para Gagné6-8, a aprendizagem pode ser compreendida como uma mudança de estado interior que se manifesta por meio da mudança de comportamento e na persistência dessa mudança. Um observador externo pode reconhecer que houve aprendizagem quando observa a ocorrência de uma mudança comportamental e também a permanência dessa mudança. A aprendizagem é uma mudança que não se deve à maturação de estruturas ou à influência fisiológica (por exemplo, efeitos do crescimento). De fato, só se pode dizer que a aprendizagem efetivamente ocorreu quando seus efeitos tornam-se observáveis.
Gagné $^{7}$ tece uma longa crítica à teoria formulada por Piaget, uma das mais difundidas e empregadas em todo o mundo. 0 primeiro ponto de discordância refere-se ao método clínico piagetiano, considerado frágil por Gagné. Tal método não permitiria muitas generalizações e dificultaria o emprego de suas concepções em contextos diferenciados. A adaptação cognitiva proposta por Piaget dependeria de fatores maturacionais e do crescimento, ligados fundamentalmente às aquisições e mudanças da estrutura biológica consolidadas com o decorrer do tempo. Já para Gagné, a criança progride porque aprende pelos processos de diferenciação e de transferência da aprendizagem. Rejeitando uma explicação maturacionista para a aprendizagem, o foco proposto por Gagné é justamente nos processos de discriminação, retenção e transferência da aprendizagem.

Assim, compreende a aprendizagem como sequencial, partindo do mais simples para o mais complexo: a criança aprende regras e propriedades mais simples para depois compreender as mais complexas, sendo necessário aprender primeiro os conceitos para depois aprender as regras complexas que os envolvem. Utilizando experimentos de aprendizagem com crianças, a exemplo dos realizados por Piaget, Gagné defende que a criança tem a aprendizagem obstruída não porque não sabe o que é conservação, seriação e reversibilidade, por exemplo, mas porque ainda não domina os conceitos de volume, altura, largura, ou seja, noções mais simples e que oferecem suporte à aprendizagem de relações mais complexas ${ }^{7}$. Assim, pode-se resumir o posicionamento de Gagné em relação à aprendizagem como o foco nas sequências de aprendizagem e nas aprendizagens prévias, bem como em sua transferência.

O autor apresenta cinco categorias de aprendizagem ou resultados principais da aprendizagem como tipos diferentes de habilidades aprendidas ${ }^{6-8}$ : (a) informação verbal; (b) estratégias cognitivas; (c) habilidades intelectuais; (d) habilidades motoras; (e) atitudes. Em relação à primeira 
categoria, se aprende uma determinada informação verbal quando é possível repetir uma sequência correta de palavras apresentadas ou reproduzir as ideias principais de uma mensagem, por exemplo, o que envolve a ação de componentes cognitivos. A informação verbal é considerada o resultado da aprendizagem que mais tem despertado a atenção dos professores, podendo ser expressa na forma de uma sentença.

Já as estratégias cognitivas referem-se ao uso de ferramentas cognitivas (pensamento, atenção, memória, percepção) para a resolução de problemas, por exemplo, de modo a escolher percursos mais adequados às necessidades da pessoa, ou seja, são os "meios específicos pelos quais as pessoas dirigem seu funcionamento intelectual"14 (p. 413). A aquisição dessas habilidades pode se dar a partir de um planejamento ou pode ocorrer de modo abrupto. São habilidades que parecem ser autoaprendidas, embora os sistemas educacionais (escolas, programas de formação) invistam fortemente nesse resultado da aprendizagem.

As habilidades intelectuais envolvem conceitos, regras e procedimentos. Segundo Gagné, uma pessoa adquiriu uma habilidade intelectual quando está apta a aplicar uma sequência de conceitos em outras situações. Esse é o resultado da aprendizagem sobre o qual Gagné mais conferiu importância, uma vez que se relaciona com as "habilidades envolvidas na aquisição da informação, resolução de problemas, descoberta de regras e aprendizado da fala"14 (p. 414).

As habilidades motoras envolvem o uso e o controle dos músculos, requerem treino e repetição de movimentos, portanto, exigem a aprendizagem pelo movimento, pela ação motora. Exemplos dessas habilidades são a escrita, a fala, a participação em atividades físicas e de recreação ${ }^{14}$. A motricidade também está relacionada a componentes emocionais, de modo que determinadas posturas ou movimentos podem contribuir para a compreensão de diferentes estados emocionais. A noção de corporeidade empregada em alguns estudos da Psicologia do Desenvolvimento parte tanto do componente motor (por exemplo, o que uma criança consegue fazer, se consegue andar, falar, expressar-se), quanto da significação desse ator motor no meio social, o que pode contribuir para a circunscrição de determinadas práticas discursivas e para a compreensão de práticas educativas que incidem sobre o desenvolvimento ${ }^{17}$.

Assim, a atitude é um estado interno que influencia a escolha de uma ação pessoal, apresentando componentes cognitivos e emocionais. É considerada um dos construtos mais investigados na ciência psicológica devido ao seu componente cognitivo e de aprendizagem social ${ }^{18,19}$. As atitudes podem ser compreendidas como reações afetivas que podem ser positivas ou negativas e cujo papel motivacional tem grande valor ${ }^{14}$. A imitação é uma das formas mais estudadas de aquisição de atitudes.

\section{RESULTADOS E DISCUSSÃO}

O primeiro evento instrucional proposto por Gagné destaca a necessidade de ganhar a atenção do aluno, de modo a despertá-lo para a importância de aprender sobre determinado conteúdo ${ }^{7,14}$. No caso em apreço, de um curso de pós-graduação em desenvolvimento regional sustentável, essa preparação ocorre já na divulgação do processo seletivo para a especialização. Os possíveis candidatos leem o edital da seleção, têm acesso a informações sobre o curso, como a ementa das disciplinas, sequência de conteúdos e estratégias de ensino, aprendizagem e avaliação. A partir disso, manifestam interesse e realizam a seleção por meio de prova de conhecimentos em raciocínio lógico e Língua Portuguesa. Com o início das matrículas, informações mais específicas são repassadas aos futuros alunos, de modo que estes possam se envolver mais efetivamente no contexto do curso, potencializando suas motivações e criando interesse pelo processo (curso) que será iniciado. 
Essa preparação é oferecida tanto pela organização na qual atuam (é o banco que divulga o curso e destaca a sua importância organizacional, que frequentemente está alinhado às estratégias e metas estabelecidas pela instituição a médio e longo prazos), quanto pelas instituições ofertantes do curso, no sentido de proporcionar informações concretas sobre o mesmo e sua operacionalização. Nesse sentido, os futuros alunos podem se sentir motivados tanto pela possibilidade de ascensão na carreira (informação veiculada pela organização), quanto pelo interesse em realizar um curso na modalidade a distância (informação veiculada pelas instituições ofertantes do MBA). Assim, o processo de preparação para a aprendizagem pode ser compreendido de modo mais amplo, desde o delineamento inicial sobre a necessidade do curso (políticas de treinamento, desenvolvimento e educação da organização) até as informações detalhadas sobre o curso, sua organização, início, duração, ferramentas e professores envolvidos. Todos esses aspectos são importantes para preparar o aluno para a aprendizagem no novo curso.

0 segundo evento refere-se à necessidade de informar aos alunos os objetivos da aprendizagem, que podem estar diluídos em diferentes conteúdos e diferentes temas. Ao iniciar um tema de estudo, os alunos devem ser informados claramente sobre quais os objetivos de aprendizagem daquele determinado tema. Os objetivos servem para nortear o processo de aprendizagem, destacando para os alunos quais os principais pontos de atenção ao novo conteúdo, bem como o sentido e a importância desses conhecimentos para a sua formação ${ }^{8}$. Desse modo, durante a leitura do material (em apostilas impressas ou em arquivos digitais), o aluno pode direcionar sua atenção, para que atinja, ao final da leitura, a compreensão necessária sobre determinado tema.

A definição dos objetivos de aprendizagem deve ser executada pela equipe pedagógica do curso, de modo a potencializar determinados aspectos no aluno que se pretende formar. Isso não significa que o aluno não possa percorrer diferentes caminhos ou que não possa se concentrar em aspectos distintos sobre o mesmo tema. De fato, é apresentado ao aprendente uma determinada sequência, que segue um pressuposto da aprendizagem que para Gagné: parte-se do mais simples, dos conceitos, para a complexidade das relações estabelecidas entre diferentes conceitos ${ }^{6,7}$.

Delimitar rigorosamente os objetivos, de modo claro, conciso e direto, é uma tarefa a qual os educadores devem se dedicar com afinco, com vistas a organizarem e planejarem uma sequência de aprendizagem considerada ideal. Em um curso de desenvolvimento regional sustentável, por exemplo, apenas para compreender o título do MBA é necessário iniciar por leituras sobre sustentabilidade. A partir disso, outros conceitos mais complexos poderão ser adquiridos, como empowerment, desenvolvimento local, estratégias de sustentabilidade, práticas de gestão social, e outros.

0 terceiro evento refere-se à recordação das aprendizagens anteriores. Esse evento dialoga diretamente com os conhecimentos já internalizados propostos por Vigotski ${ }^{20}$, de modo que toda a aprendizagem não parte de um ponto zero, mas de um já-dito, de um já-sabido, ou seja, parte das aprendizagens anteriores relacionadas ao novo conteúdo que será apresentado. Como destacado por Vigotski ${ }^{20}$, toda nova aprendizagem deve dialogar com as aprendizagens anteriores, de modo que estas possam funcionar como base para que novos conteúdos possam ser adquiridos ou apropriados. Em Gagné, as aprendizagens anteriores funcionam como estruturas cognitivas que dão suporte para que novos conhecimentos possam ser adquiridos, de modo que recuperá-los é um passo importante para que os alunos possam selecionar as estruturas já internalizadas e que os auxiliarão na tarefa de aprendizagem. Essa vinculação com os conhecimentos já internalizados possibilita que os alunos 
também estabeleçam conexões que facilitem a aprendizagem.

Esse processo de recuperação da informação para a aquisição de novos conhecimentos destaca a própria sequência de aprendizagem proposta por Gagné, em que os conteúdos vão se organizando de maneira hierárquica e em grau crescente de complexidade. No curso analisado, esse evento fica claro na sequência das disciplinas e na sequência de temas ministrados dentro de uma mesma disciplina. A cada novo conteúdo ou tema introduzido em uma dada disciplina, são recuperadas as aprendizagens já realizadas. Esses conhecimentos prévios podem ser recuperados por meio de um resumo inicial no início de um novo tema ou por meio de uma chamada do professor da videoaula, em que os conteúdos anteriores oferecem suporte para a aprendizagem atual e, são destacados de modo breve. Essa estratégia de recuperação ativa mecanismos cognitivos de memória, de modo que a nova aprendizagem será processada com maior sentido, pois dialogará intimamente com que o aluno já sabe, já conhece e já adquiriu.

0 quarto evento refere-se à apresentação ao aluno do material a ser aprendido. É o chamado estímulo, que pode se dar a partir de uma apostila, de um livro, videoaula, videoconferência, entre outros. Todos os materiais utilizados na EAD devem ser organizados de modo a atender a determinados princípios, como atenção à linguagem, ao layout dos materiais, ao modo como os conteúdos são organizados e apresentados. Em determinados treinamentos ou mesmo em curso de formação a distância, o modo de apresentar ao aluno o estímulo pode ser determinante da permanência do aluno e da conclusão do curso. A atenção ao estímulo não se refere apenas aos aspectos chamados estéticos, mas também de organização didática.

Há que se reconhecer que a aprendizagem em cursos de EAD não pode ser comparada aos modelos presenciais, pois partem de pressupostos educacionais distintos e atendem a diferentes objetivos, de modo que buscar apenas uma transição de mídias (da sala de aula para a plataforma de aprendizagem) pode ser um fator dificultador do processo de aprendizagem. Há que se desenvolver estratégias específicas para a EAD, haja vista que a própria comunicação a partir das NTIC muda o modo como nos comunicamos quando entramos em contato com os outros. Uma interação em um fórum de discussão não ocorre da mesma forma se for colocado os mesmos alunos em uma sala de reuniões e lhes se apresentar uma questão norteadora. 0 fundamental é reconhecer que as pessoas aprendem e interagem de modos distintos, de forma que reconhecer esse aspecto e construir estratégias em EAD é uma forma de potencializar a aprendizagem. Assim, o estímulo não é apenas a forma, o material, mas também o desenho instrucional mais amplo.

0 quinto evento refere-se a proporcionar ao aluno orientação para a aprendizagem, com o propósito de auxiliar os estudantes a compreenderem, organizarem e perceberem a importância de usar a codificação semântica (verbalização) ${ }^{11}$. Essa orientação pode se dar de diferentes formas: por meio de orientações gerais e específicas a cada nova atividade ou por meio de documentos gerais que informam os alunos sobre as regras das ferramentas de aprendizagem e sobre a organização do curso, por exemplo.

As orientações são comuns nos manuais do curso e mesmo nos materiais didáticos, como lembretes em apostilas ou pequenas chamadas em videoaulas, com a proposta de orientar a aprendizagem do aluno enquanto ele assiste às aulas. São comuns também os esquemas, as ilustrações, as sistematizações dos conhecimentos em apreço que podem se referir tanto a determinados conteúdos como à própria organização do curso. Um exemplo dessa segunda possibilidade é apresentado na Figura 1, que representa o modelo de funcionamento das atividades avaliativas no MBA em desenvolvimento regional sustentável. 
Figura 1. Atividades do MBA em Desenvolvimento Regional Sustentável

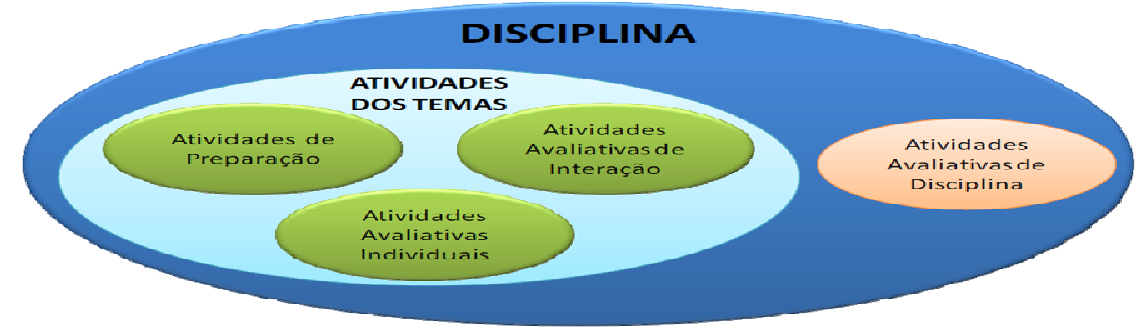

A partir dessa visualização, segundo pressupostos de Gagné, o aluno consegue ativar mecanismos cognitivos que favorecem a retenção da informação e a sua consequente aprendizagem. Desse modo, a maior parte dos cursos em EAD faz uso desses esquemas para potencializar a aprendizagem, favorecendo que a mesma ocorra de modo mais rápido.

0 sexto evento refere-se a eliciar o desempenho, ou seja, a resposta esperada, permitindo ao aprendente demonstrar a aprendizagem ou os problemas da aprendizagem por meio do estímulo à memorização, às aplicações, resumos e generalizações. Os alunos podem ser convidados a escrever no próprio material, a trazer exemplos, tentar aplicar os conhecimentos aprendidos em situações práticas. Um exemplo refere-se ao campo reservado nas apostilas do curso de pósgraduação em desenvolvimento regional sustentável para que o aluno anote as suas impressões e elabore resumos sobre os conteúdos aprendidos, como observado na Figura 2.

Figura 2. Espaço disponibilizado na apostila do MBA em desenvolvimento regional sustentável para que os alunos façam anotações e resumos.

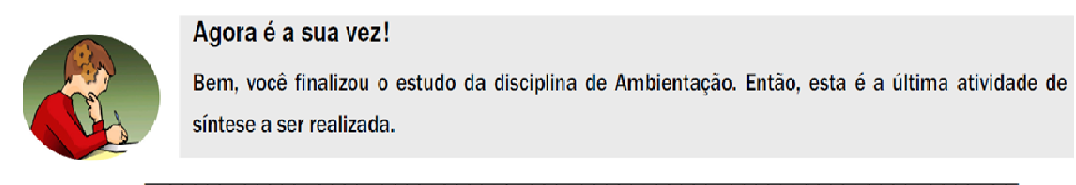

Atualmente, outras ferramentas tecnológicas têm sido empregadas, como a wiki ${ }^{21}$, ou mesmo ferramentas de edição presentes em tablets, por exemplo, de modo que os comentários dos alunos possam alterar o texto da apostila, sendo compartilhados pela rede e podendo orientar também outros alunos. Desse modo, observase que o desenvolvimento e aperfeiçoamento das NTIC têm possibilitado releituras, inclusive, dos eventos instrucionais de Gagné.

0 sétimo evento refere-se aos feedbacks, que seriam uma espécie de devolutiva ou de avaliação do aluno acerca do seu desempenho nas diferentes atividades do curso, com o objetivo de proporcionar ao aprendente o reforçamento pelo esforço da aprendizagem $^{22}$. No modelo em discussão, foi introduzida a mensagem de tutoria, que é um espaço criado pelos tutores do curso para oferecer feedbacks coletivos, organizados por turmas. Essas mensagens são compostas pelos tutores e endereçadas às diferentes turmas do curso, formadas por cerca de 30 alunos. Nas mensagens, os tutores comentam detalhadamente cada uma das atividades realizadas pelos alunos durante a semana, 
retomando os objetivos de cada avaliação e analisando o desempenho dos alunos de modo coletivo, sem exposição dos rendimentos individuais. Essa avaliação é apreciativa no sentido de destacar os pontos fortes das avaliações, bem como os processos já adquiridos e internalizados pela turma. Mas também são trazidos os pontos que merecem ser priorizados pelas turmas em futuras aprendizagens, os aspectos ainda não plenamente desenvolvidos e as estruturas que merecem maior atenção por parte dos alunos.

Trata-se de um processo de avaliar como a turma tem evoluído no curso e como ela pode potencializar a sua aprendizagem a partir do investimento nas diferentes ferramentas de interação. Os feedbacks também são oferecidos individualmente, caso algum aluno faça essa solicitação ao tutor, mas segundo os pressupostos do modelo pedagógico do curso, as devolutivas coletivas são capazes de posicionar os alunos ${ }^{22}$, de modo que eles possam compartilhar e interagir no ambiente virtual de aprendizagem. Desse modo, retira-se da EAD um caráter por vezes intimista, individual e solitário associado aos alunos dessa modalidade, de modo que a aprendizagem não ocorre apenas de modo isolado, mas também compartilhado e de forma colaborativa.

O feedback, no curso em apreço, funciona não apenas como um reforçamento dos comportamentos mais adequados ou desejáveis, mas de posturas de aprendizado que destacam o perfil do aluno que se pretende formar, ou seja, de gestores sociais. Assim, percebe-se que esse evento ganha destaque no presente curso justamente por se alinhar aos objetivos de formação profissionais perseguidos pela organização contratante do curso.

0 oitavo evento refere-se à avaliação do desempenho. No curso estudado, existem diferentes formas de avaliação, em atenção à necessidade de diversificação, de modo a possibilitar que os alunos possam exercitar seus conhecimentos em tarefas distintas e com objetivos igualmente diferenciados.
Nesse processo, diferentes formas de aprender podem ser favorecidas, haja vista que ferramentas com delineamentos distintos eliciam respostas também diferentes.

O desempenho é avaliado por meio da participação em fóruns de discussão, painéis de opiniões, respostas às perguntas de videoaulas, questionários e conteúdos dinâmicos, para citar apenas as principais estratégias avaliativas. Cada uma dessas ferramentas possui diferentes objetivos e requerem estratégias cognitivas específicas mais relacionadas à memorização, à retenção ou mesmo à transferência. Por exemplo, o fórum de discussão apresenta uma proposição sem uma resposta única e leva os alunos a discutirem e assumirem diferentes posicionamentos. Essas reflexões são mediadas por tutores, de modo a fomentar que as discussões alinhem-se aos conteúdos do curso, encorajando a assunção de posicionamentos críticos, que formem um aluno capaz de se posicionar de forma crítica, de exercitar outros posicionamentos, de promover mudanças na sua aprendizagem e, consequentemente, em sua prática da gestão social.

O novo e último evento instrucional refere-se ao estímulo, à retenção e à transferência da aprendizagem, com o propósito de proporcionar ao aprendente oportunidades de aplicar e generalizar o aprendido, atuando em diferentes contextos de prática. A transferência da aprendizagem tem sido investigada por muitos pesquisadores, notadamente da área de Psicologia Organizacional e do Trabalho, no contexto dos treinamentos oferecidos a distância ${ }^{18,23}$.

Os processos de transferência são importantes justamente para que os cursos potencializem a aprendizagem contínua e autônoma dos alunos. Esse estímulo pode ser incrementado de diferentes modos, tanto por meio de avaliações regulares como da possibilidade de que os alunos egressos de cursos a distância possam empregar seus conhecimentos em seu cotidiano. No caso do curso de formação em desenvolvimento 
regional sustentável, essa vinculação com a prática é fornecida logo após o aluno concluir o curso, pois aos egressos é oferecida a oportunidade de trabalhar diretamente nessa área do banco (gestão social), empregando os conhecimentos adquiridos. Os profissionais formados nesse curso também podem realizar palestras e capacitações para outros funcionários, de modo a disseminar os conhecimentos do curso para grande contingente de pessoas, também consideradas em formação.

Para Gagné7, a transferência é inerente ao aprendiz, de modo que a se conseguir transferir as situações ou as sequências iguais ou semelhantes. Por isso a importância da residencial social na formação dos gestores, haja vista que não se trata apenas de um estágio, mas do planejamento, intervenção e avaliação de um projeto em uma comunidade regional com foco na sustentabilidade. Os alunos não apenas empregam os conhecimentos adquiridos no curso nessa residência, mas trazem para os diferentes fóruns do curso os problemas ou as soluções encontradas no campo empírico. Desse modo, prima-se pelo diálogo entre teoria e prática, o que é fundamental na concepção de aprendizagem de Gagné. Essa aproximação pode e deve estar presente não apenas na gestão social, como priorizado no presente estudo, mas também em diferentes setores de atuação, como o da saúde pública ${ }^{5}$, no ímpeto de que os profissionais possam não apenas destacar suas experiências, como dotá-las de maior poder de mudança.

\section{CONCLUSÃO}

Ao considerar a aplicação dos eventos instrucionais de Gagné em um curso a distância, pode-se compreender as possibilidades e limites dessa aproximação. Entre as principais contribuições da teoria da aprendizagem de Gagné para a educação a distância, pode-se afirmar que os eventos instrucionais oferecem um enquadre teóricometodológico para que os cursos na modalidade a distância possam ser pensados com rigor e planejamento adequado. Isso pode favorecer um ensino de maior qualidade, promovendo processos de aprendizagens cada vez mais complexos e que proporcionem transformações significativas no desenvolvimento.

Uma das limitações da utilização da teoria de Gagné para a educação a distância está em organizar e sistematizar a aprendizagem em contextos nos quais 0 público-alvo não é previamente conhecido, ou seja, em cursos que são oferecidos de modo aberto. Embora alguns aspectos possam ser incluídos no perfil do aluno que se deseja selecionar, a diversidade pode dificultar a execução de determinados eventos, notadamente os que se referem à transferência. A transferência da aprendizagem para outros contextos pode ser uma dificuldade encontrada nos treinamentos a distância. Assim, há que se considerarem esses diferentes contextos no projeto instrucional do curso, embora essa consideração nem sempre possa ser realizada de maneira adequada ou controlada.

Entre as possibilidades do emprego dos eventos instrucionais na EAD, pode-se destacar a construção de parâmetros claros e objetivos, permitindo que um mesmo curso seja replicado em outras situações. Apesar dessa sistematização, os modelos pedagógicos não são herméticos e permitem o diálogo aberto com os alunos para que transformações sejam realizadas ao longo do percurso da aprendizagem. Sem dúvida, um repertório concreto de sequências e métodos pode conduzir à aprendizagem, mas é necessário que se reflita constantemente sobre a transferência do que é aprendido. Nessa perspectiva, transferir conhecimento é também aprender, contribuindo para fortalecer o processo de transformação. Nesse contexto, abre-se a necessidade de formação de educadores capacitados não a aplicar o método proposto por Gagné de modo automático, mas de planejar, desenvolver e avaliar propostas de cursos e treinamentos. 


\section{REFERÊNCIAS}

1. Lévy P. Cibercultura. Costa CI, tradutor. 3ed. São Paulo: Ed. 34; 2011.

2. Coll C, Bustos A, Engel A. As comunidades virtuais de aprendizagem. In: Coll C, Monereo C, organizadores. Psicologia da educação virtual: aprender e ensinar com as tecnologias da informação e da comunicação. Freitas N, tradutora. Porto Alegre: Artmed; 2010. p. 268-86.

3. França CL, Matta KW, Alves ED. Psicologia e educação a distância: uma revisão bibliográfica. Psicol Ciênc Prof. [Internet]. 2012 [citado em 15 fev 2015]; 32(1): 4-15. Disponível em: http://www.scielo.br/pdf/pcp/v32n1/v32n1a02.p df.

4. Scorsolini-Comin F, Santos MA. Bakhtin e os processos de desenvolvimento humano: um diálogo de, no mínimo, duas vozes. Rev Bras Crescimento Desenvolv Hum. 2010; 20(3):805-17.

5. Atrash K, Carpentier R. The evolving role of public health in the delivery of health care. Rev Bras Crescimento Desenvolv Hum. 2012; 22(3):396-9.

6. Gagné RM. The acquisition of knowledge. Psychol Rev. 1962; 69(4):355-65.

7. Gagné RM. Contributions of learning to human development. Psychol Rev. 1968; 75(3): 177-91.

8. Gagné RM. Learning outcomes and their effects: useful categories of human performance. Am Psychol. 1984:377-85.

9. Gagné RM, Briggs LJ, Wagner WW. Principles of instructional design. 3ed. Nova York: Holt, Rinehart \& Winston; 1988.

10.Gagné RM, Medsker KL. The conditions of learning: training applications. Fort Worth, TX: Harcout Brace; 1996.

11.Gagné RM, Smith Jr. EC. A study of the effects of verbalization on problem solving. J Exp Psychol. 1962; 63(1):12-8.

12. Scorsolini-Comin F, Inocente DF, Matias AB. Análise de ferramentas de interação e comunicação em ambiente virtual de aprendizagem a partir de contribuições de Bakhtin. Educ Teor Prát. 2009; 19(32): 173-89.

13. Fischer T. Gestão do desenvolvimento e poderes locais: marcos teóricos e estratégias de avaliação. Salvador: Casa da Qualidade; 2002.

14. Lefrançois GR. Teorias da aprendizagem. Magyar V, tradutora. 5ed. São Paulo: Cengage Learning; 2008.

15. Santrock JW. Psicologia educacional. Durante D et al., tradutores. 3ed. São Paulo: McGrawHill; 2009.
16. Alavarce DC, Pierin AMG. Elaboração de uma hipermídia educacional para o ensino do procedimento de medida da pressão arterial. Rev Esc Enferm USP. [Internet]. 2011 [citado em $15 \mathrm{fev}$ 2015]; 45(4):939-44. Disponível em: http://www.scielo.br/pdf/reeusp/v45n4/v45n4a2 1.pdf. doi:http://dx.doi.org/10.1590/S008062342011000400021.

17. Scorsolini-Comin F, Amorim KS. Em meu gesto existe o teu gesto: corporeidade na inclusão de crianças deficientes. Psicol Reflex Crít. [Internet]. 2010 [citado em 15 fev 2015]; 23(2):261-69. Disponível em: http://www.scielo.br/pdf/prc/v23n2/v23n2a08.p df. doi:http://dx.doi.org/10.1590/S010279722010000200008

18. Zerbini T, Abbad G. Estratégias de aprendizagem em curso a distância: validação de uma escala. Psico USF. 2008 ; 13(2):177-87.

19. Steil AV, Pillon AE, Kern VM. Atitudes com relação à educação a distância em uma universidade. Psicol Estud. [Internet]. 2005 [citado em 15 fev 2015]; 10(2):253-62. Disponível em: http://www.scielo.br/pdf/pe/v10n2/v10n2a12.pdf doi: http://dx.doi.org/10.1590/S141373722005000200012.

20. Vigotski LS. Pensamento e linguagem. São Paulo: Martins Fontes; 1987.

21.Cyrino AP, Amaral VM, Espósito ACC, Garcia VL, Cyrino EG, Zornoffet DCM. Ensino na comunidade e inteligência coletiva: partilhando saberes com o WIKI. Rev Bras Educ Med. [Internet]. 2012 [citado em 15 fev 2015]; 36(1): 64-70. Disponível em: http://www.scielo.br/pdf/rbem/v36n1s1/v36n1s1 a09.pdf. doi: http://dx.doi.org/10.1590/S010055022012000200009.

22. Abreu-e-Lima DM, Alves MN. O feedback e sua importância no processo de tutoria a distância. ProPosições [Internet]. 2011 [citado em 15 fev 2015]; 22(2):189-205. Disponível em: http://www.scielo.br/pdf/pp/v22n2/v22n2a13.pd f. doi: http://dx.doi.org/10.1590/S010373072011000200013.

23. Abbad G, Zerbini T, Souza DBL. Panorama das pesquisas em educação a distância no Brasil. Estud Psicol. [Internet]. 2010 [citado em 15 fev 2015]; 15(3):291-8. Disponível em: http://www.scielo.br/pdf/epsic/v15n3/a09v15n3. pdf. doi: http://dx.doi.org/10.1590/S14132940X2010000300009.

Scorsolini-Comin e Manoel Antônio dos Santos tiveram iguais contribuições no desenho, análise e redação final do artigo. 